\title{
Evaluation of an integrated sponge - granular activated carbon fluidized bed bioreactor for treating primary treated sewage effluent
}

\author{
W. Xing ${ }^{\text {a }}$, H. H. Ngo ${ }^{a^{*}}$, W. S. Guo ${ }^{a}$, A. Listowski ${ }^{\text {b }}$ P. Cullum ${ }^{c}$ \\ ${ }^{a}$ Centre for Technology in Water and Wastewater, School of Civil and Environmental \\ Engineering, FEIT, University of Technology Sydney, Broadway, NSW 2007, Australia \\ ${ }^{\mathrm{b}}$ Sydney Olympic Park Authority, Sydney Olympic Park, NSW 2127, Australia \\ ${ }^{c}$ Activated Carbon Technologies Pty Ltd, Eltham VIC 3095, Australia \\ * Corresponding author Email: h.ngo@uts.edu.au
}

\begin{abstract}
An integrated fluidized bed bioreactor (iFBBR) was designed to incorporate an aerobic sponge FBBR (ASB-FBBR) into an anoxic granular activated carbon FBBR (GAC-FBBR). This iFBBR was operated with and without adding a new starch based flocculant (NSBF) to treat synthetic primary treated sewage effluent (PTSE). The NSBF contains starch based cationic flocculants and trace nutrients. The results indicate that the iFBBR with NSBF addition could remove more than $93 \%$ dissolved organic carbon (DOC), 61\% total nitrogen (T-N) and 60\% total phosphorus (T-P) at just a very short
\end{abstract}


hydraulic retention time of 50 minutes. The optimum frequency of adding NSBF to the iFFBR is 4 times per day. As a pretreatment to microfiltration, the iFFBR could increase $5 \mathrm{~L} / \mathrm{m}^{2}$.h of critical flux thus reducing the membrane fouling. In addition, better microbial activity was also observed with high DO consumption $(>66 \%)$ and specific oxygen uptake rate (>35 $\mathrm{mg} \mathrm{O}_{2} / \mathrm{g}$ VSS.h).

Keywords: Fluidized bed bioreactor, primary treated sewage effluent, granular activated carbon, sponge, starch based flocculant

\section{Introduction}

Fluidized bed bioreactor (FBBR) has played a vital role in terms of achieving simultaneous organic and nutrients removals (Xing et al., 2010; Lohi et al, 2007; Patel et al., 2006). FBBR combines some outstanding features of conventional wastewater treatment process, such as trickling filters and activated sludge. FBBR involves attached growth on the inner and outer surfaces of small supporting media fluidized in suspension either pneumatically or mechanically (Guo et al., 2010). FBBRs have several advantages over other treatment systems such as: i) immobilization of microorganisms on small, porous fluidized media as biofilms results in higher biomass concentration in FBBR compared to activated sludge (Karapina and Kargi, 1995); ii) reducing hydraulic retention time (HRT) with high treatment efficiency (Saravanane and Murthy, 2000); iii) fluidization overcomes operating problems such as bed clogging, 
high pressure drop, poor mixing and oxygen transfer which are commonly encountered in fixed bed bioreactor (Shieh and Keenan, 1986); and iv) biofilm supporting carriers are excellently contacted with the liquid phase and provide larger surface area for nutrient transfer (Mowla and Ahmadi, 2007).

The most significant variable in digestion of FBBR is the selection of supporting media for microbial adhesion (Arnaiz et al., 2006), which normally have three different types: (i) inert cores on which a biofilm is created by cells attachment or, in the case of enzymes by adsorption or covalent binding immobilization; (ii) porous particles in which the biocatalysts are entrapped; (iii) cell aggregates obtained by self-immobilization, due to the ability of some cell strains to form flocs, pellets, or aggregates (Godia and Sola, 1995). It was reported that many supporting media have been used in FBBR such as granular activated carbon (GAC), sand, perlite, zeolite, lava rocks and sponge with considerably successful application (Sowmeyan et al., 2008; Fernandez et al., 2007; Yu and Luo., 2002). As a biological attachment medium, GAC has excellent biomass retention owing to the extensive surface area and sheltering capabilities. Additionally, GAC has advantage as the capacity to adsorb the contaminants to the reactor. In GAC-FBBR, the adsorbed organics are biodegraded by microorganisms attached on GAC and could release the active sites that allow the further adsorption. Therefore, the adsorption capacity of GAC protects the attached biofilm from shock organic loading and GAC is also ideal for rapid biomass colonization and could provide the shelter from shear force (Pruden et al., 2003; 
Maloney et al., 2002; Safferman and Bishop, 1997). Maloney et al. (2002) demonstrated a pilot scale anaerobic FBBR containing GAC to treat a pinkwater consists of trinitrotoluene (TNT) and royal demolition explosive (RDX) as well as other hazardous by-products. The results showed that TNT and RDX could be effectively treated by anaerobic bacteria under widely varied contaminant concentrations. Moreover, sponge was also investigated as one of ideal attached-growth supporting media in FBBR. Normally, biomass retains on sponge in two different forms: thick and dense- biofilm developed onto the sponge cube surfaces, and deposited or entrapped forms in the interior void space of the sponge cubes (Araki et al., 1999). Guo et al. (2010) showed the scanning electron microscope (SEM) results of clean and acclimatized sponge where the sponge acted as an ideal support for biofilm growth. The sponge is highly porous and can keep high concentration of biomass in the bioreactor. Guo et al. (2010) evaluated the sponge moving bed bioreactor in terms of organic and nutrients removals. It was observed that the sponge moving bed bioreactor eliminated $100 \%$ of total phosphorus (T-P).

The natural based flocculants are environmental friendly and biodegradable, as well as present good flocculating ability. They can minimize the environmental and health risks and have attracted more attention in water and wastewater treatments. The advantages of the natural based flocculant are: (i) virtually toxic free; (ii) biodegradable in the environment; (iii) the raw products are often locally available, whereas industrialized flocculants may not be; and (iv) the sludge from flocculation may be 
reused (Rizzo et al., 2008; Bratby, 2006). As biodegradable flocculant can provide the carbon source biodegradation, the additives are helpful for biomass growth and to enhance the microbial activities in biological process for wastewater treatment (Xing et al., 2010).

In this study, an integrated FBBR (iFBBR) was proposed to incorporate an aerobic sponge bioreactor FBBR (ASB-FBBR) to an anoxic granular activated carbon FBBR (GAC-FBBR). It was then used to treat synthetic primary treated sewage effluent (PTSE) with adding a new starch based flocculant (NSBF). The main objectives of this study are: (i) to evaluate the performance of iFBBR in terms of organic and nutrients removals from synthetic primary treated sewage effluent (PTSE) together with biomass and microbial activity, and (ii) to investigate the effect of NSBF addition in FBBR for treating PTSE.

\section{Materials and Methods}

\subsection{Materials}

\subsubsection{Wastewater}

The synthetic wastewater used in this study originally contains biodegradable organic pollutants together with some trace nutrients, which was used to simulate PTSE after primary treatment process. The refractory organic pollutants (ROPs) in PTSE contains natural organic matters such as humic acid, tannic acid, lignin, polysaccharide and other high molecular carbohydrates, which contribute about $10 \mathrm{mg} / \mathrm{L}$ dissolved 
organic matter to PTSE. The synthetic PTSE has DOC of 90-105 mg/L, total nitrogen (T-N) of $17.5-20 \mathrm{mg} / \mathrm{L}$ and T-P of $2.9-3 \mathrm{mg} / \mathrm{L}$.

\subsubsection{GAC used}

The coal based GAC, ACTICARB GS1300 from Activated Carbon Technologies Pty Ltd, Australia, was used in this study. This coal based GAC has a surface area of $>1100 \mathrm{BETm}^{2} / \mathrm{g}$, an iodine number of $>1100 \mathrm{mg} /(\mathrm{g} \cdot \mathrm{min})$ and maximum ash content of $10 \%$. Prior to use in experiments, the GAC was rinsed with distilled water to remove fines and dried at $105^{\circ} \mathrm{C}$ in the oven.

\subsubsection{Sponge}

The reticulated polyester urethane sponge S28-30/90R from Joyce Foam Products, Australia, was used in this study. The sponge has the density of $28-30 \mathrm{~kg} / \mathrm{m}^{3}$, the tensile strength and tear resistance are $150 \mathrm{kPa}$ and $650 \mathrm{~N} / \mathrm{m}$, respectively. And the cell count is $90 \pm 10$ cells per $25 \mathrm{~mm}$.

\subsubsection{New starch based flocculant (NSBF)}

The NSBF used in this study is a combination of nature starch based cationic flocculant (SBCF) and trace nutrients $\left(\mathrm{CaCl}_{2}, \mathrm{MgSO}_{4}\right.$ and $\left.\mathrm{FeCl}_{3}\right)$ which are helpful for biomass growth. The starch based cationic flocculant was provided by HYDRA 2002 Research, Development and Consulting Ltd., Hungary. The major components of this 
flocculant are cationic starch ether and water. It is completely soluble in water with a density of $1050 \mathrm{~kg} / \mathrm{m}^{3}$.

\subsection{Experimental set-up of specific FBBR}

In this study, laboratory-scale iFBBR was designed to incorporate an aerobic sponge bioreactor (ASB-FBBR) to an anoxic granular activated carbon FBBR (GAC-FBBR). Two iFBBRs were used to run in parallel. $200 \mathrm{~mL}$ of fresh GAC was added into each GAC-FBBR to have an actual (non-fluidized) filter depth of $500 \mathrm{~mm}$. PTSE was fed into GAC-FBBR at a flow rate of $28.8 \mathrm{~L} /$ day whilst fluidization of GAC was achieved through recycling the effluent from near the top of sponge bioreactor to the bottom assembly. Meanwhile, $800 \mathrm{~mL}$ of sponge cubes, $10 \times 10 \times 10 \mathrm{~mm}$, was directly added into each ASB-FBBR, and the sponge bioreactor was equipped with air diffusers. The air bubbles helped in supplying oxygen to the microbial mass for biological activities as well as fluidizing sponge. The organic loading rate (OLR) and hydraulic retention time (HRT) were operated at $8.64 \mathrm{~kg} \mathrm{COD} /$ day $\cdot \mathrm{m}^{3}$ and 50 minutes, respectively. The HRT of GAC-FBBR and ASB-FBBR was maintained at 10 and 40 minutes, respectively. In addition, based on the amount of wastewater to be treated per day $(28.8 \mathrm{~L} / \mathrm{d})$, the total amount of $849.8 \mathrm{mg}-\mathrm{NSBF} / \mathrm{d}$ was added into one of the iFBBRs at different frequency (e.g. $849.8 \mathrm{mg}$ per time/d; $424.9 \mathrm{mg}$ per time for two times/d; $212.45 \mathrm{mg}$ per time for 4 times/d, $106.22 \mathrm{mg}$ per time for 8 times/d and $70.82 \mathrm{mg}$ per time for 12 times/d). The samples of feedings and the effluents from iFBBRs were taken and passed through 0.45 
$\mu \mathrm{m}$ filter prior to analyzing DOC and nutrients.

\subsection{Submerged microfiltration (SMF) hybrid system}

The hydrophilic polyethylene hollow fiber microfiltration membrane with pore size of $0.1 \mu \mathrm{m}$ and surface area of $0.05 \mathrm{~m}^{2}$ was used in this study. The PTSE or the effluent from an iFBBR was delivered to the membrane reactor by a feeding pump. The air was supplied to the membrane reactor at a flow rate of $8 \mathrm{~L} / \mathrm{min}$. The permeate flow rate was controlled by a suction pump. Flux-step method was applied to determine the critical flux (Le Clech, 2003). With the synthetic PTSE or pretreated PTSE, the flux-step experiments were carried out at a step height of $5 \mathrm{~L} / \mathrm{m}^{2} \cdot \mathrm{h}$ and duration of 60 minutes with the initial flux of $10 \mathrm{~L} / \mathrm{m}^{2} . \mathrm{h}$. When the filtration period was finished (after 60 minutes), the membrane was backwashed with the distilled water at the flux of 30 $\mathrm{L} / \mathrm{m}^{2}$.h for $1 \mathrm{~min}$. After each experiment, the membrane was chemically cleaned by firstly immersed in $1 \% \mathrm{HCl}$ solution for 2 hours to remove the calcium. The membrane was then submerged in $2 \%$ citric acid for 2 hours to remove iron, aluminum and manganese attachments from the membrane. Finally, the membrane was submerged in $0.4 \% \mathrm{NaOCl}$ and $4 \% \mathrm{NaOH}$ solution for 2 hours to remove silica and organic matter.

\subsection{Analysis}

DOC of the influent and effluent was measured using the Analytikjena Multi N/C 2000 analyzer. The biomass was monitored as mixed liquor volatile suspended solids 
(MLVSS) and was measured according to Standard Methods (APHA, 1998). In order to measure the biomass, three samples were taken each time and the average value was recorded. The microbial activity of the biomass was tested by the dissolved oxygen (DO) consumption rate using YSI 5300 biological Oxygen Monitor. The oxygen uptake rate (OUR) and specific oxygen uptake rate (SOUR) were calculated by means of a linear regression analysis of dissolved oxygen against time (Said-Pullicino and Gigliotti, 2007). $\mathrm{NH}_{4}-\mathrm{N}, \mathrm{NO}_{3}-\mathrm{N}, \mathrm{NO}_{2}-\mathrm{N}, \mathrm{T}-\mathrm{N}$ and T-P were measured by photometric method called Spectroquant ${ }^{\circledR}$ Cell Test using Merck NOVA 60.

\section{Results and Discussion}

\subsection{Performance of iFBBR}

\subsubsection{Biomass and microbial activity}

The DO concentration was controlled around $2.5 \mathrm{mg} / \mathrm{L}$ for the aerobic condition in ASB-FBBR and $<0.5 \mathrm{mg} / \mathrm{L}$ in the recirculation tank to ensure that GAC was under anoxic environment during the operation period. The $\mathrm{pH}$ value of the feeding PTSE was always kept at 7.5 to 8 and no further $\mathrm{pH}$ adjustment was employed for the system. During the operation days, the pH stayed at the range 6 to 7 for both of the recirculation tank and ASB-FBBR, while the ORP remained above $150 \mathrm{mv}$ in the ASB-FBBR. Furthermore, the ORP of GAC-FBBR was remained around -100 mv which indicates that the GAC-FBBR was operated under anoxic condition. The biomass attached on the sponge was measured on the $3^{\text {rd }}, 7^{\text {th, }} 10^{\text {th }}$ days and every 5 days afterwards. As shown in 
Table 1 , the systems performed stably from the $15^{\text {th }}$ day of the operation, the DO consumption was $66 \%$ with the biomass of $161 \mathrm{mg}$ biomass $/ \mathrm{g}$ sponge on the $30^{\text {th }}$ day. The acting of biomass appears very high oxygen uptake rate (OUR) and SOUR, which indicated the good microbial activities during operation period, e.g. $9.86 \mathrm{mg} \mathrm{O} / \mathrm{L} . \mathrm{h}$ and $35.22 \mathrm{mg} \mathrm{O}_{2} / \mathrm{g}$ VSS.h, respectively.

\section{Table 1}

DO consumption, sponge biomass, OUR and SOUR in the iFBBR with NSBF addition

\subsubsection{Organic and nutrients removals}

Figure 1 presents the organic and nutrients removals for the 30 days operation. The FBBR with NSBF addition showed the stable performance in terms of DOC removals (93\%-94\%) from the $7^{\text {th }}$ day, while the FBBR remained stable for nutrients removals from the $15^{\text {th }}$ day. On the $30^{\text {th }}$ day, the T-N and T-P removals from PTSE were achieved to $61 \%$ and $60 \%$, respectively. As the NO3-N and NO2-N in the effluent were less than 0.4 and $0.01 \mathrm{mg} / \mathrm{L}$, it demonstrates that the iFBBR itself has a function of simultaneous nitrification and denitrification (SND). Compared with GAC-FBBR alone (Xing et al., 2010), the iFBBR could increase the removal efficiencies of DOC, T-P and T-N by 37\%, $26 \%$ and $24 \%$, respectively. It indicated that the aerobic sponge reactor played an important role in organic and nutrients removals. The previous study also found the aerobic sponge moving bed bioreactor achieved $51.7 \%$ of T-N and $89.1 \%$ of T-P 
removal from synthetic wastewater (Guo et al., 2010).

Figure 1 Organic and nutrients removals in specific iFBBR with NSBF addition (influent DOC $=90-105 \mathrm{mg} / \mathrm{L}, \mathrm{T}-\mathrm{P}=2.9-3 \mathrm{mg} / \mathrm{L}, \mathrm{NH}_{4}-\mathrm{N}=16.5-19.0 \mathrm{mg} / \mathrm{L}, \mathrm{NO}_{2}-\mathrm{N}=$ 0-0.02 mg/L, $\mathrm{NO}_{3}-\mathrm{N}=0.8-1 \mathrm{mg} / \mathrm{L}, \mathrm{T}-\mathrm{N}=17.5-20 \mathrm{mg} / \mathrm{L}$ )

\subsubsection{Mass balance}

Eqs. (1) and (2) were used to determine the mass balance in the GAC-ASB FBBR. Eq.

(1) was used to calculate the mass of nitrogen and phosphorus, and the total mass of nitrogen is the sum of the masses of $\mathrm{NH}_{4}-\mathrm{N}$ and $\mathrm{NO}_{X}-\mathrm{N}$ (Eq.(2)).

$$
\begin{array}{ll}
M=Q \times C & \text { Eq.(1) } \\
M_{N}=M_{N H_{4}}+M_{N O_{x}} & \text { Eq.(2) }
\end{array}
$$

The nitrogen in the influent passed through the GAC-ASB FBBR, and left in the water effluent or were removed by denitrification in anoxic GAC-FBBR and nitrification in aerobic ASB-FBBR.

$$
M_{\text {input }}=M_{\text {output }}+M_{G A C-F B B R}+M_{A S B-F B B R} \quad \text { Eq.(3) }
$$

All the mass removal rates are calculated as the difference between input and output mass rate, and the positive value reflect removal while negative value means generation. Based on the ammonia removal rate, approximately $190.08 \mathrm{mg} /$ day $\mathrm{NH}_{4}-\mathrm{N}$ were nitrified in the aerobic sponge tank and $25.92 \mathrm{mg} / \mathrm{L} \mathrm{NO}_{3}-\mathrm{N}$ was removed by 
denitrification in anoxic GAC-FBBR. The mass balance was summarized in Figure 2. It was showed anoxic GAC-FBBR removed $138.24 \mathrm{mg} /$ day T-N while the following aerobic sponge achieved 184.32 T-N removal. In iFBBR, the anoxic GAC-FBBR allows the phosphate-accumulating organisms (PAOs) attached on GAC to take up VFAs into their cells and store them as poly-a-hydroxybuterate (PHF), around $43.73 \mathrm{mg} /$ day of T-P was consumed as the energy source in the GAC-FBBR. Meanwhile, in the aerobic sponge FBBR, the stored PHF is oxidized by the PAOs for cell growth and to provide energy for reforming polyphosphate. By going through both anoxic and aerobic conditions in iFBBR, $49.54 \mathrm{mg} /$ day of T-P was removed totally.

Figure 2 Mass balances in the iFBBR

\subsubsection{IFBBR as pretreatment to submerged microfiltration (SMF)}

The performance of iFBBR as pretreatment to submerged microfiltration (SMF) was evaluated in terms of critical flux. The experimental set-up of submerged microfiltration (SMF) hybrid system was described in section 2.3. The flux-step experiments were carried out at a step height of $5 \mathrm{~L} / \mathrm{m}^{2} . \mathrm{h}$ and duration of 60 mins with the initial flux of $10 \mathrm{~L} / \mathrm{m}^{2} . \mathrm{h}$. The results show that the system with pretreatment could improve the permeability of membrane. Without any pretreatment, the critical flux of PTSE alone was only $15 \mathrm{~L} / \mathrm{m}^{2}$.h. In a case of using iFBBR without adding NSBF, the critical flux was increased to $20 \mathrm{~L} / \mathrm{m}^{2} . \mathrm{h}$. When adding NSBF, the critical flux of $25 \mathrm{~L} / \mathrm{m}^{2} \cdot \mathrm{h}$ was achieved. Hence, both iFBBR and NSBF could successfully help in reducing the 
membrane fouling and led to higher critical flux.

\subsection{Effect of NSBF addition to iFBBR}

Two iFBBRs were carried out in parallel. NSBF was iFBBR continuously added in one of the iFBBRs. Figure 3 illustrates the performance comparison of iFBBR with and without NSBF addition in terms of microbial activities. With NSBF addition, higher biomass attached on sponge resulted in higher DO consumption, higher OUR and SOUR e.g. 66.2\%, $9.86 \mathrm{mg} \mathrm{O2/L.h} \mathrm{and} 35.22 \mathrm{mg} \mathrm{O} / \mathrm{g}$ VSS.h, respectively. Better microbial activities were achieved. Meanwhile, the biomass attached on GAC with the NSBF addition reached to $5.15 \mathrm{~g} / \mathrm{L}$ while it was only $4.75 \mathrm{~g} / \mathrm{L}$ for that of the GAC without NSBF addition. The more active biomass was attached, the better performance of iFBBR could be achieved. The overall efficiency of FBBR was enhanced by up to $10 \%$. The previous study on anaerobic FBBR also proved that NSBF is a performance enhancer and could increase organic and nutrients removal ability (Xing et al., 2010). Thus, NSBF is helpful to improve the performance of iFBBR because NSBF can provide extra carbon source and trace nutrients to promote the microorganism growth. Based on the previous studies, the addition of carbon source and trace nutrients are necessary for the biomass growth in the iFBBR. (Cresson et al., 2006; Georgiou and Aivasidis, 2006).

Figure 3 Performance comparison of the iFBBR with and without NSBF addition 


\subsection{Frequency of adding NSBF}

\subsubsection{Biomass and microbial activity}

The frequency of adding NSBF to GAC-ASB FBBR was increased from once per day (NSBF-1) to 12 times per day (NSBF-12). Figure 4 shows the sponge biomass and SOUR with different NSBF addition frequencies. As shown in Figure 4, with NSBF addition twice per day (NSBF-2), the DO consumption for 20 mins was $57.5 \%$ and $65.4 \%$ with the biomass of 194.55 and $196.84 \mathrm{mg}$ biomass $/ g$ sponge on the $10^{\text {th }}$ and $15^{\text {th }}$ day.

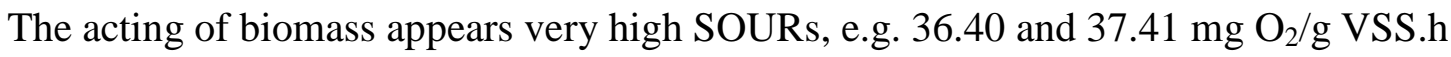
which indicated the good microbial activities during the operation period. After 15 days operation, the frequency of adding NSBF was changed to four times per day (NSBF-4), under which the biomass and SOUR were $207.44 \mathrm{mg}$ biomass $/ \mathrm{g}_{\text {sponge }}$ and $35.57 \mathrm{mg} \mathrm{O} / \mathrm{g}$ VSS.h, respectively, on the $15^{\text {th }}$ day. Furthermore, the biomass of sponge and SOUR were $170.62 \mathrm{mg}$ biomass/g sponge and $35.38 \mathrm{mg} \mathrm{O} / \mathrm{g}$ VSS.h after changing the NSBF adding frequency to eight times per day (NSBF-8). The GAC-ASB FBBR was operated with 12 times per day NSBF addition (NSBF-12) for another 15 days. The observed less sponge biomass, $172.88 \mathrm{mg}$ biomass/g sponge, lower SOUR, $26.90 \mathrm{mg} \mathrm{\textrm {O } _ { 2 }} / \mathrm{g}$ VSS.h and DO consumption, $41 \%$, indicated the worse microbial activities resulted by NSBF-12. It could be found out that the FBBR with NSBF-4 showed the best microbial activity, which is indicated by DO consumption of $69.8 \%$, biomass of $207.44 \mathrm{mg}$ biomass $/ \mathrm{g}$ sponge and SOUR of $35.57 \mathrm{mg} \mathrm{O}_{2} / \mathrm{g}$ VSS.h. The amount of NSBF added to iFBBR per day was maintained the same in terms of quality and quantity during the experiments but the adding frequency of NSBF was varied, in other words, the availability of the NSBF at a 
given time was different. Kumar et al. (2010) found that the availability of nutrients at a certain time determined the biomass productivity response. Thus, the biomass has its own optimum requirement for carbon source and nutrients. It might be a reason why the decrease of microbial activity presented at NSBF-8 and NSBF-12.

Figure 4 Biomass and microbial activity with the different frequency of NSBF addition

\subsubsection{Organic and nutrients removals}

Figure 5 summarizes the organic and nutrients removals of the iFBBR with different NSBF adding frequencies. The FBBR with NSBF-2, NSBF-4, NSBF-8 and NSBF-12 shows stable performance on DOC removal (>90\%) during the operation period. Meanwhile, the T-N and T-P removals from PTSE were achieved to 51\% and 59\% on the 15th day, which are similar to nutrients removals for the GAC-ASB FBBR with NSBF-1 at the same day under the same operation condition (58\% of T-N and $58 \%$ of T-P). In addition, the FBBR with NSBF-4 and NSBF-8 resulted in slightly higher nutrients removals, e,g, $64 \%$ of T-N and $62 \%$ of T-P. With the increase of NSBF addition frequency to NSBF-12, the organic removal efficiency decreased slightly. Meanwhile, T-N removal efficiency increased to $75.18 \%$. The NSBF-8 and NSBF-12 only led to slightly better in the organic and nutrients removals compared to those of NSBF-4. However, the iFBBR with NSBF-8 and NSBF-12 was high cost as it consumed much more chemicals and energy, NSBF-4 also resulted in highest microbial 
activity. Therefore, the optimum frequency for adding NSBF could be NSBF-4.

Figure 5 Organic and nutrients removal of the iFBBR with NSBF addition (influent DOC $=90-105 \mathrm{mg} / \mathrm{L}, \mathrm{T}-\mathrm{P}=2.9-3 \mathrm{mg} / \mathrm{L}, \mathrm{NH}_{4}-\mathrm{N}=16.5-19.0 \mathrm{mg} / \mathrm{L}, \mathrm{NO}_{2}-\mathrm{N}=0-0.02 \mathrm{mg} / \mathrm{L}$, $\left.\mathrm{NO}_{3}-\mathrm{N}=0.8-1 \mathrm{mg} / \mathrm{L}, \mathrm{T}-\mathrm{N}=17.5-20 \mathrm{mg} / \mathrm{L}\right)$

\section{Conclusions}

The specific findings in this study are as follows:

Specific iFBBR was successful in removing the organic and nutrients from synthetic PTSE;

Addition of NSBF was helpful for biomass growth and to enhance the performance of GAC-ASB FBBR in terms of organic and nutrients removals.

The optimum frequency of adding NSBF to the iFBBR is identified as 4 times per day (NSBF-4).

Further study on the optimization of HRT is essential.

\section{Acknowledgements}

This research project was funded by ARC linkage project (LP 0775149). The authors are grateful to the support of Sydney Olympic Park Authority (SOPA), Activated Carbon Technologies Pty Ltd, UTS Chancellor's Postdoctoral Research Fellowship and UTS Early Career Researcher Grants. The authors also thank HYDRA 
2002 Research, Development and Consulting Ltd., Hungary for providing the starch based cationic flocculant.

\section{References}

APHA. 1998. Standard Methods for the Examination of Water and Wastewater. 20th ed. Washington, DC: American Public Health Association.

Araki, N., Ohashi, A., Machdar, I., Harada, H., 1999. Behaviours of nitrifiers in a novel biofilm reactor employing hanging sponge-cubes as attachment site. Water Science and Technology 39(7), 23-31.

Arnaiz, C., Gutierrez, J.C., Lebrato, J., 2006. Support material selection for anaerobic fluidized bed reactors by phospolipid analysis. Biochemical Engineering Journal $27,240-245$.

Bratby, J., 2006. Coagulation and flocculation in water and wastewater treatment. 2nd Ed.; IWA Publishing: London, UK.

Cresson, R., Carrere, H., Delgenes, J.P., Bernet, N., 2006. Biofilm formation during the start-up period of an anaerobic biofilm reactor-Impact of nutrient complementation. Biochemical Engineering Journal 30, 55-62.

Fernandez, N., Montalvo, S., Guerrero, L., Sanchez, E., Cortes, I., Travieso, L., 2007. Anaerobic fluidized bed reactor application to tropical fruit wine effluent. Water Science and Technology 56, 33-38.

Georgiou, D., Aivasidis, A., 2006. Decoloration of textile wastewater by means of a 
fluidized-bed loop reactor and immobilized anaerobic bacteria. Journal of Hazardous Materials 135, 372-377.

Godia, F., Sola, C., 1995. Fluidized bed. Biotechnology Program 11, 479-497.

Guo, W.S., Ngo, H.H., Dharmawan, F., Palmer, C.G., 2010. Roles of polyurethane foam in aerobic moving and fixed bed bioreactors. Biorrsource Technology 101, 1435-1439.

Kumar, M.S., Miao, Z.H., Wyatt, S.K., 2010. Influence of nutrient loads, feeding frequency and inoculum source on growth of Chlorella vulgaris in digested piggery effluent culture medium. Bioresource Technology 101, 6012-6018.

Le Clech, P., B. Jefferson, I.S. Chang, and S.J. Judd., 2003. Critical Flux Determination by the Flux-step Method in a Submerged Membrane Bioreactor. Journal of Membrane Science 227, 81-93.

Lohi, A., Cuenca, M. A., Anania, G., Upreti, S. R., Wan, L., 2007. Biodegradation of diesel fuel-contaminated wastewater using a three-phase fluidized bed reactor. Journal of Hazardous Materials (in press).

Maloney, S.W., Adrian, N.R., Hickey, R.F., Heine, R.L.,2002. Anaerobic treatment of pinkwater in a fluidized bed reactor containing GAC. Journal of Hazardous Materials 92, 77-88.

Mowla, D., Ahmadi, M., 2007. Theoretical and experimental investigation of biodegradation of hydrocarbon polluted water in a three-phase fluidized-bed bioreactor with pvc biofilm support. Biochemical Engineering Journal 36, 147-156. 
Patel, A., Zhu, J. Nakahla, G., 2006. Simultaneous carbon, nitrogen and phosphorous removal from municipal wastewater in a circulating fluidized bed bioreactor. Chemosphere 65, 1103-1112.

Rizzo, L., Lofrano, G., Grassi, M., Belgiorno, V., 2008. Pre-treatment of olive mill wastewater by chitosan coagulation and advanced oxidation process. Separation and Purification Technology 63(3), 648-653.

Said-Pullicino, D., Gigliotti, G., 2007. Oxidative biodegradation of dissolved organic matter during composting. Chemosphere, 68, 1030-1040.

Saravanane, R., Murthy, D.V.S., 2000. Application of anaerobic fluidized bed reactors in wastewater treatment: a review. Environment Management and Health 11(2), 97-117.

Shieh, W.K., Keenan, J.D., 1986. Fluidized bed biofilm reactor for wastewater treatment. Advanced in biochemical engineering /biotechnology, Springer-Verlag New York Inc, 33, 131-169

Sowmeyan, R., Swaminathan, G., 2008. Evaluation of inverse anaerobic fluidized bed reactor for treating high strength organic wastewater, Bioresource Technology 99, 3877-3880.

Wang, X.J., Xia, S.Q., Chen, L., Zhao, J.F., Renault, N.J., Chovelon, J.M., 2006. Nutrients removal from municipal wastewater by chemical precipitation in a moving bed biofilm rector. Process Biochemistry 41, 824-828.

Xing, W., Ngo, H.H., Guo, W.S., Wu, Z.Q., Nguyen, T.T., Cullum, P., Listowski, A., 
Yang, N., 2010. Enhancement of the performance of anaerobic fluidized bed bioreactors (AFBBRs) by a new starch based flocculant. Seperation and Purification Technology 72, 140-146.

Yu, P., Luo, Y., 2002. Noval water treatment process-combined cationic ion-exchange bed and degasifier in a three-phase fluidized bed. Desalination 151, $145-152$. 
Table 1

DO consumption, sponge biomass, OUR and SOUR in the iFBBR with NSBF addition

\begin{tabular}{ccccc}
\hline Day & $\begin{array}{c}\text { DO consumption } \\
\text { for 20 mins }(\%)\end{array}$ & $\begin{array}{c}\text { Sponge biomass } \\
\left(\mathrm{mg}_{\text {biomass }} / \mathrm{g}_{\text {sponge }}\right)\end{array}$ & $\begin{array}{c}\text { OUR } \\
(\mathrm{mg} \mathrm{O2} / \mathrm{L} . \mathrm{h})\end{array}$ & $\begin{array}{c}\text { SOUR } \\
(\mathrm{mg} \text { o2/ g vss.h })\end{array}$ \\
\hline 3 & 40.9 & 89.12 & 2.76 & 13.79 \\
5 & 65.2 & 107.14 & 6.57 & 34.55 \\
7 & 65.2 & 90.82 & 6.57 & 32.83 \\
10 & 57.3 & 149.53 & 7.15 & 32.51 \\
15 & 65.2 & 159.32 & 6.57 & 32.83 \\
20 & 62.3 & 160.37 & 9.5 & 33.94 \\
25 & 66.4 & 169.17 & 9.91 & 34.18 \\
30 & 66.2 & 160.55 & 9.86 & 35.22 \\
\hline
\end{tabular}




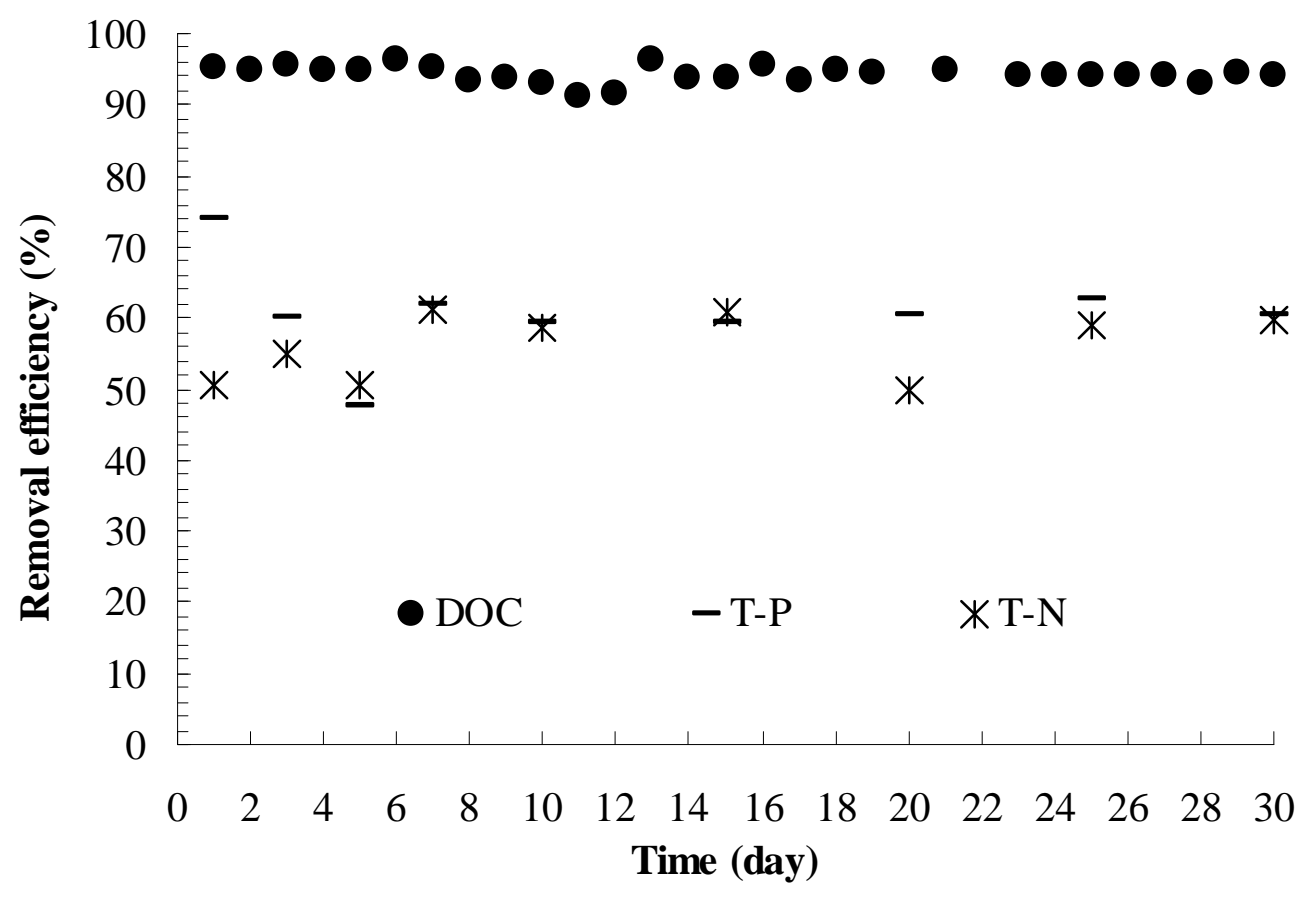

Figure 1 Organic and nutrients removals in specific iFBBR with NSBF addition (influent DOC $=90-105 \mathrm{mg} / \mathrm{L}, \mathrm{T}-\mathrm{P}=2.9-3 \mathrm{mg} / \mathrm{L}, \mathrm{NH}_{4}-\mathrm{N}=16.5-19.0 \mathrm{mg} / \mathrm{L}, \mathrm{NO}_{2}-\mathrm{N}=$ $0-0.02 \mathrm{mg} / \mathrm{L}, \mathrm{NO}_{3}-\mathrm{N}=0.8-1 \mathrm{mg} / \mathrm{L}, \mathrm{T}-\mathrm{N}=17.5-20 \mathrm{mg} / \mathrm{L}$ ) 


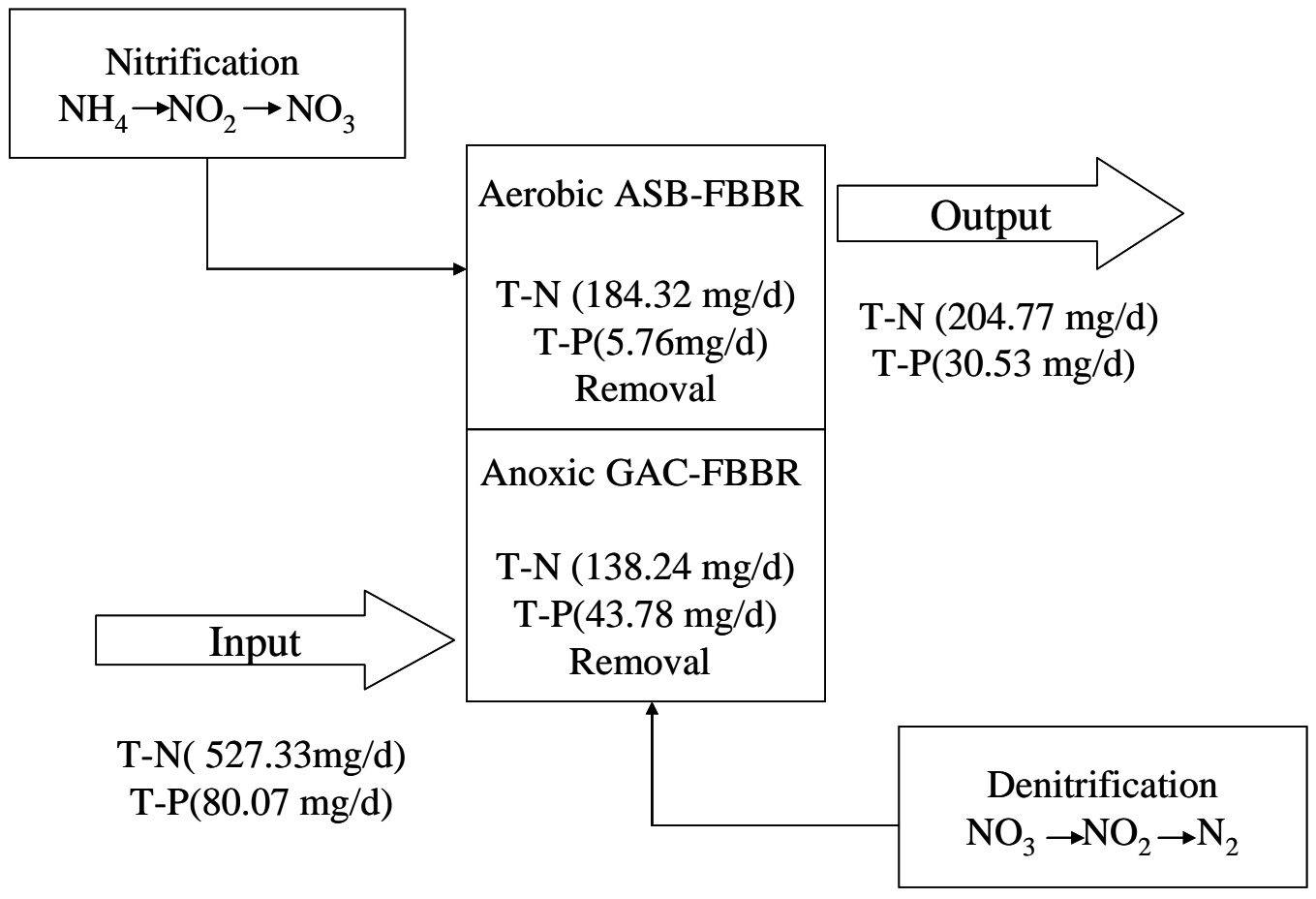

Figure 2 Mass balances in the iFBBR 

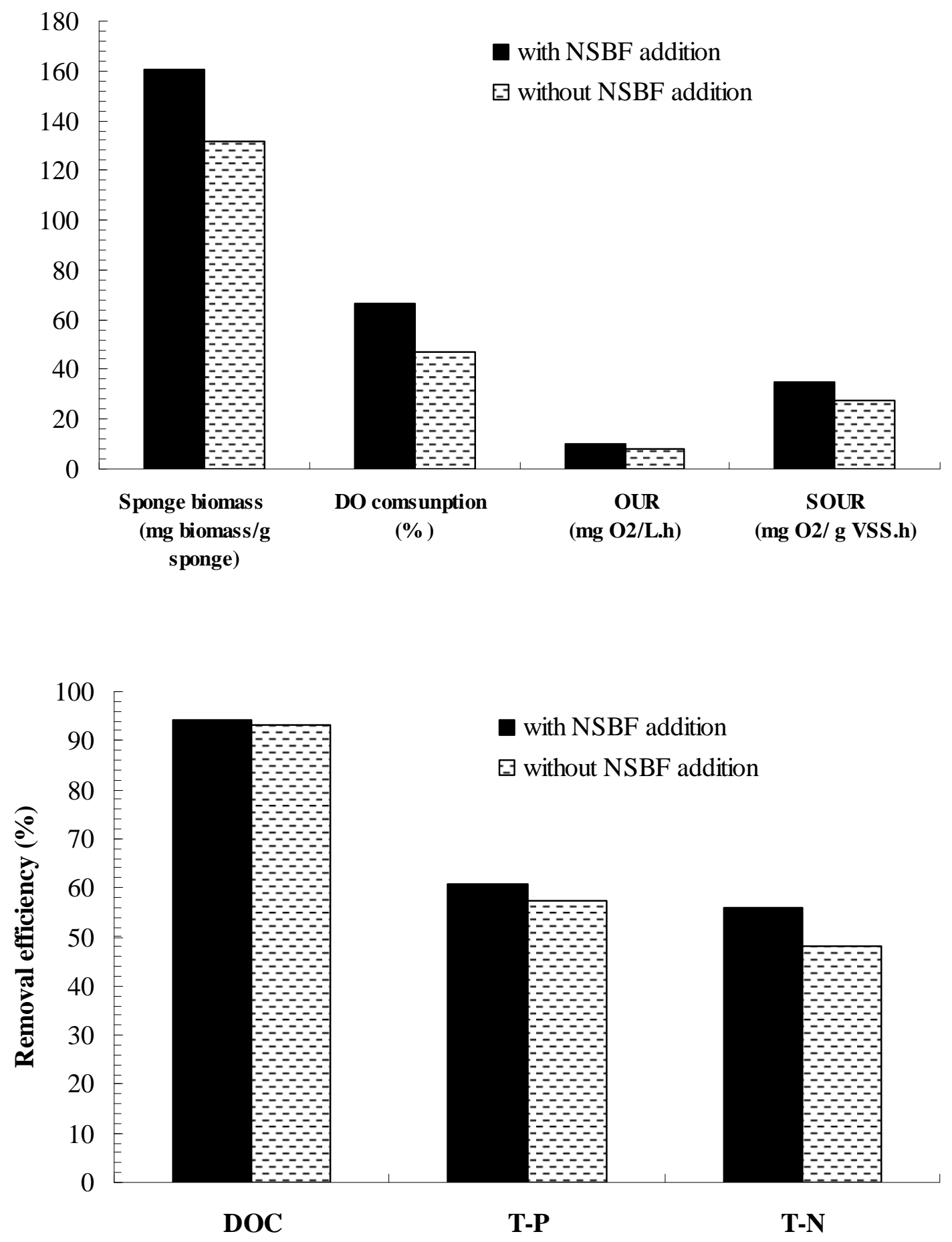

Figure 3 Performance comparison of the iFBBR with and without NSBF addition 


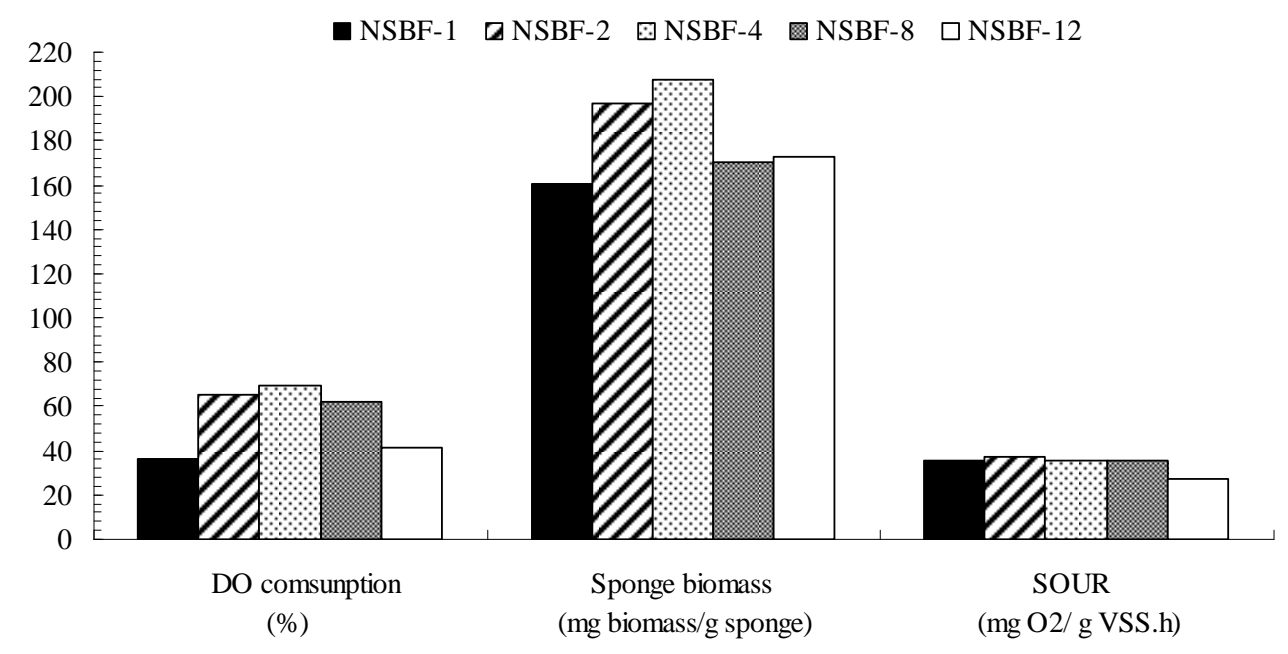

Figure 4 Biomass and microbial activity with the different frequency of NSBF addition 


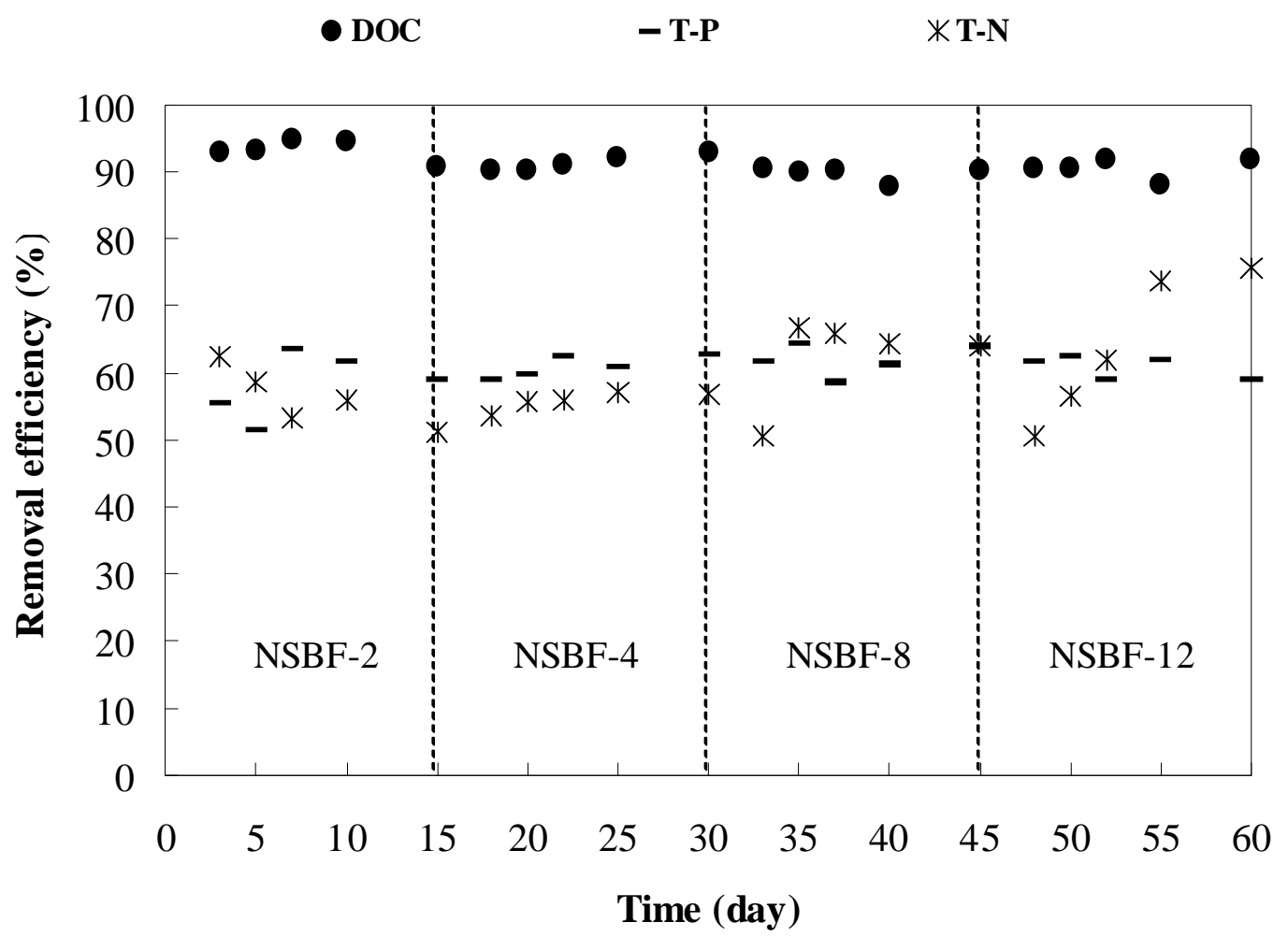

Figure 5 Organic and nutrients removal of the iFBBR with NSBF addition (influent $\mathrm{DOC}=90-105 \mathrm{mg} / \mathrm{L}, \mathrm{T}-\mathrm{P}=2.9-3 \mathrm{mg} / \mathrm{L}, \mathrm{NH}_{4}-\mathrm{N}=16.5-19.0 \mathrm{mg} / \mathrm{L}, \mathrm{NO}_{2}-\mathrm{N}=0-0.02 \mathrm{mg} / \mathrm{L}$, $\left.\mathrm{NO}_{3}-\mathrm{N}=0.8-1 \mathrm{mg} / \mathrm{L}, \mathrm{T}-\mathrm{N}=17.5-20 \mathrm{mg} / \mathrm{L}\right)$ 